\title{
ETNO-HISTÓRIA-ORAL: A SOBREVIVÊNCIA DE UMA INDÍGENA KAINGANG À ÉPOCA DA DITADURA MILITAR BRASILEIRA. RELIGIÃO E PROTAGONISMO
}

Leandro Seawright ${ }^{1}$

Resumo: Neste artigo estão registrados fragmentos de uma narrativa de história oral concedida por Maria, uma indígena Kaingang de São Jerônimo da Serra, no norte do Paraná. Memórias de sofrimentos pessoais e familiares foram narradas e analisadas na presente investida acadêmica. Também as estratégias de negociações religiosas e vivências culturais se apresentaram na abordagem.

Palavras-chave: História Indígena; História Oral; Etnografia; Discurso.

\section{ETNO-HISTÓRIA-ORAL: THE SURVIVAL OF A KINGINGANG INDIGENOUS TO THE TIME OF THE BRAZILIAN MILITARY DICTATORSHIP. RELIGION AND PROTAGONISM}

\begin{abstract}
In this article were recorded fragments of an oral history narrative granted by Maria, a Kaingang indigenous of São Jerônimo da Serra, in the north of Paraná. Memories of personal and family suffering were narrated and analyzed in this academic investiture. Also the strategies of religious negotiations and cultural experiences presented themselves in the approach.

Keywords: Indigenous History; Oral History; Memory; Ethnography; Speech.

\section{ETNO-HISTORIA-ORAL: LA SUPERVIVENCIA DE UNA INDÍGENA KAINGANG A LA ÉPOCA DE LA DITADURA MILITAR BRASILEÑA. RELIGIÓN Y PROTAGONISMO}

Resumen: En este artículo se registraron fragmentos de una narrativa de historia oral concedida por María, una indígena Kaingang de San Jerónimo da Serra, en el norte de Paraná. Las memorias de sufrimientos personales y familiares fueron narradas y analizadas en la presente investidura académica. También las estrategias de negociaciones religiosas y vivencias culturales se presentaron en el abordaje.

Palabras clave: Historia Indígena; Historia Oral; Memoria; Etnografía; Discurso.

\section{PROPOSTAS E DELIMITAÇÕES}

Antes de ler os resultados do importante relatório Violações de Direitos Humanos dos Povos Indígenas, redigido como produto das investidas de Grupo de

\footnotetext{
1 Pós-Doutorando e Doutor em História Social pela Universidade de São Paulo - FFLCH/USP. Coordenador do Núcleo de Estudos em História Oral - NEHO/USP. Foi pesquisador da Comissão Nacional da Verdade, CNV. E-mail: leandroneho@gmail.com
} 
Trabalho especializado, GT, da Comissão Nacional da Verdade, CNV, sobre Graves Violações de Direitos Humanos no Campo ou contra os Indígenas ${ }^{2}$, encetei, por meio de uma rede de indicações na região norte do Estado do Paraná, a busca por uma indígena que desde antes do período da ditadura militar brasileira (NAPOLITANO, 2014), viveu em São Jerônimo da Serra. Sem a pretensão de retraçar, aqui, o histórico dos Kaingang - como o "mais populoso grupo indígena do Sul do Brasil” (MOTA In TOMMASINO; MOTA; NOELLI, 2004, p. 3 - 16) -, e a fundamental questão de Terras Indígenas, TIs (MOTA, 1997; 2014; 2000), proponho apresentar fragmentos de uma entrevista de história oral realizada em perspectiva etnográfica para uma análise tenra sobre (I) as graves violações de direitos humanos cometidas à indígena Kaingang em evidência e à sua família, (II) as molduras da experiência religiosa que oportunizou sobrevivência ao "modus operandi" da ditadura militar brasileira, a qual afetou comprovadamente a população indígena no país, assim como (III) os contornos de subjetividade que urdiram a sua narrativa. Tudo, por lógico, na perspectiva de que a indígena ouvida em situação de entrevista assumiu o seu protagonismo não apenas diante da elementar inserção étnica em regimes de historicidade característicos de seu pertencimento, mas como quem moldou a própria narrativa e se apropriou da memória no âmbito da consciência histórica com consequências notáveis. Sem abdicar dos ecos prementes e constantes de John Monteiro (1994), que, com fulcro em outros cortes temporais, conferiu inteligibilidade à historiografia indígena por meio do caráter cognoscível das tramas entre os índios e os europeus, não se pretende tratar o protagonismo da indígena em questão de maneira trivial ou porque tem sido tendência oportuna grafar a palavra ou o conceito. Sem incorrer no vício de muitas repetições da expressão mencionada, ao longo do texto pretende-se que a voz e a vez da indígena ouvida se faça valer em suas teias complexas na luta pela sobrevivência; ao fim, importa que o protagonismo da indígena ouvida se faça presente mais do que teoricamente, e, como disse João Pacheco de Oliveira por outras razões e por motivos aquilatados, nos “conjuntos de relações estabelecidas entre indígenas e os demais atores e forças sociais que com eles interagiam" (2016, p. 7).

Os estudos sobre as graves violações de direitos humanos ganharam dimensões alargadas e, por conseguinte, entraram em um estágio de latência em face do incômodo da anistia ou da inação do Estado sobre uma "efetiva política de memória" evidenciada,

\footnotetext{
${ }^{2} \mathrm{O}$ texto do relatório em questão foi elaborado sob a responsabilidade da comissionada Maria Rita Kehl.
} 
entre outras coisas, por Caroline Silveira Bauer em Como será o passado?: História, historiadores e a Comissão Nacional da Verdade (2017, p. 15). Obras, artigos e o dossiê: As memórias do regime militar no Brasil e uma justiça de transição inacabada: vozes, propostas, estudos (SEAWRIGHT; ROVAI, 2017), indicaram, por vias de temáticas distintas da história indígena, o inacabamento da justiça de transição no Brasil - uma "ferida aberta", "inflamada" e "não inteiramente tratada" no tecido social com a derradeira responsabilização do Estado aos agentes da repressão atuantes principalmente entre 1964 e 1985.

No centro da abordagem está a história oral em perspectiva etnográfica conforme propus neste ensejo, ou, como se denomina em um ensaio de ousadia, a Etnohistória-oral ${ }^{3}$, bem como os escrutínios da memória individual da indígena do caso em tela como produto da memória coletiva de uma comunidade maior (HALBWACHS, 1925; 1994); não apenas, mas inclusive a experiência religiosa cotidiana da indígena convertida ao protestantismo que, neste caso, sustentou uma narrativa sobre como os elementos místicos e cristãos ${ }^{4}$ fundamentaram ações de resistência às violações sofridas: sequestros por agentes do Estado, torturas da interlocutora e de seu marido, assim como o desaparecimento forçado do seu esposo como resposta às ações sociais de caráter político-religioso realizadas na residência da família em São Jerônimo da Serra.

A proposta que se segue ganha colorações vivazes, multivocais, transgressoras - embora dramáticas -, na análise discursiva e narrativa das experiências de violações sofridas pela indígena Kaingang e pela sua família; mas, a análise da entrevista realizada foi, outrossim, instigada pela historiografia que comprova as graves violações de direitos humanos entre as populações indígenas no período ditatorial (e mesmo antes da deflagração do arbítrio por meio do golpe de Estado de 1964), conforme o relatório da CNV supramencionado:

Os povos indígenas no Brasil sofreram graves violações de seus direitos humanos no período entre 1946 e 1988 [...] Não são

\footnotetext{
${ }^{3}$ Para uma avaliação teórico-metodológica da Etno-história à parte da Etno-história-oral, recomendo o artigo: Etno-história e história indígena: questões sobre conceitos, métodos e relevância da pesquisa, de Thiago Leandro Vieira Cavalcante (2011). Do mesmo autor, a obra: Colonialismo, Território e Territorialidade: a luta pela Terra dos Guarani e Kaiowa em Mato Grosso do Sul propicia a compreensão heurística dessa abordagem no campo da História Indígena (CAVALCANTE, 2016).

${ }^{4}$ De saída, indico, entre outras, a obra Até os confins da terra: o movimento ecumênico protestante no Brasil e a evangelização dos povos indígenas, de Carlos Barros Gonçalves (2011), para uma reflexão crítica sobre o papel social dos missionários na vivência de indígenas que tomaram contato com o cristianismo de verniz protestante. Esta obra serve para uma desnaturalização de eventuais preconcepções generalizadoras sobre o desempenho de missionários protestantes no universo dos povos indígenas.
}

Fronteiras: Revista de História | Dourados, MS | v. 19 | n. 34 | p. 280 - 301 | Jul. / Dez. 2017 
esporádicas nem acidentais essas violações: elas são sistêmicas, na medida em que resultam diretamente de políticas estruturais de Estado, que respondem por elas, tanto por suas ações diretas quanto pelas suas omissões. Omissão e violência direta do Estado sempre conviveram na política indigenista, mas seus pesos respectivos sofreram variações. Poder-se-ia assim distinguir dois períodos entre 1946 e 1988, o primeiro em que a União estabeleceu condições propícias ao esbulho de terras indígenas e

se caracterizou majoritariamente (mas não exclusivamente) pela omissão, acobertando o poder local, interesses privados e deixando de fiscalizar a corrupção em seus quadros; no segundo período, o protagonismo da União nas graves violações de direitos dos índios fica patente, sem que omissões letais, particularmente na área de saúde e no controle da corrupção, deixem de existir. Na esteira do Plano de Integração Nacional, grandes interesses privados são favorecidos diretamente pela União, atropelando direitos dos índios. A transição entre os dois períodos pode ser datada: é aquela que se inicia em dezembro de 1968, com o AI-5 (BRASIL - CNV, 2014, Vol. II, p. 198 - 199).

\section{ETNOGRAFIA E HISTÓRIA ORAL: ETNO-HISTÓRIA-ORAL.}

Ao considerar a relação entre a etnografia e a história oral, ancoro-me provisoriamente, de um prisma, em James Clifford para caracterizar sucintamente a antropologia crítica que emergiu a partir da década de 1980, e, ao mesmo tempo, na história oral conforme praticada pelo Núcleo de Estudos em História Oral - NEHO/USP (MEIHY, 2005). Implica dizer, pois, que elementos discursivos são primazes nos registros etnográficos porque pode não ser suficiente adensar uma descrição sem, entretanto, questionar o lugar epistêmico do etnógrafo, ou sua autoridade, na experiência polissêmica de campo ou em sua decorrente análise. São expoentes da antropologia crítica, entre outros, os seguintes autores: James Clifford, Georges Marcus, Michel Fischer, Richard Price e Michel Taussig.

Donde, considera-se que

Torna-se necessário conceber a etnografia não como a experiência e a interpretação de uma "outra" realidade circunscrita, mas sim como uma negociação construtiva envolvendo pelo menos dois, e muitas vezes mais, sujeitos conscientes e politicamente significativos. Paradigmas de experiência e interpretação estão dando lugar a paradigmas discursivos de diálogo e polifonia. Um modelo discursivo de prática etnográfica traz para o centro da cena a intersubjetividade de toda fala, juntamente com seu contexto performativo imediato (CLIFFORD, 2002, p. 43). 
$\mathrm{O}$ anúncio do modelo discursivo e intersubjetivo que demarca posições contemporâneas candentes de crítica antropológica, alternativamente conflui com a história oral proposta não simplesmente como metodologia de pesquisa, mas como aquela que oferece um estatuto capaz de estabelecer a memória como o seu campo de ação e a escuta como meio de interação: escutar é um ato estético e político ao mesmo tempo. Não se trata de considerar a indígena, do caso em tela, como uma "afônica" para quem o oralista "dá voz", ou, de outro ângulo, como uma agente de "invisibilidade" para quem o Etno-oralista "dá visibilidade"; tais posturas indicariam uma posição autoritária que não cabe à antropologia crítica e apontariam, ainda, para determinado arcaísmo da história oral conforme naturalmente praticada em seus primórdios.

Para José Carlos Sebe Bom Meihy e Fabíola Holanda, a história oral encontra caminhos de realização se concebida para além do "documentismo":

Em termos práticos, supondo que para muitos a história oral tem se restringido à aplicação de entrevistas dialógicas, o que se nota é o uso delas enquanto "meio" e não como "fim". A redução do uso das entrevistas à condição de fonte ou documento auxiliar rebaixa a potencialidade dos textos resultantes de gravações de maneira a neutralizá-los como se fosse um aposto aos outros suportes documentais (MEIHY; HOLANDA, 2013, p. 76).

Nesse direcionamento é que a intersecção entre a etnografia crítica e a história oral nehoísta faz sentido para os estudos de uma narrativa que se tornou - mais do que um "documento frio" armazenado ao lado de outros - instrumento da constituição de um narrador e de um narratário por meio da audição, por meio da visão, por meio da relação estabelecida por duas presenças.

Porque

[...] todo uso do pronome eu pressupõe um você, e cada instância do discurso é imediatamente ligada a uma situação específica, compartilhada; assim não há nenhum significado discursivo sem interlocução e contexto. A relevância desta ênfase para a etnografia é evidente. $\mathrm{O}$ trabalho de campo é significativamente composto de eventos de linguagem; mas a linguagem, nas palavras de Bakhtin, 'repousa nas margens entre o eu e o outro. Metade de uma palavra, na linguagem, pertence a outra pessoa' [...] As palavras da escrita etnográfica, portanto, não podem ser pensadas como monológicas, como a legitima declaração sobre, ou interpretação de uma realidade abstrata e textualizada (CLIFFORD, 2002, p. 44).

\footnotetext{
5 O emprego da expressão "documentismo", neste artigo, deriva-se das concepções de Keith Jenkins contra certa ingenuidade no tratamento da documentação no campo historiográfico (2007).
}

Fronteiras: Revista de História | Dourados, MS | v. 19 | n. 34 | p. 280 - 301 | Jul. / Dez. 2017 
Com isso, revela-se todo o potencial de uma entrevista de história oral entrecruzada com a etnografia não por elementos de precisão ou por aquilo que é análogo entre o que se diz e o que é de fato, mas por visões de mundo, por representações, por significações de experiências para além da importante textualidade geertziana e de escritos que transcendem a hermenêutica para encontrar a sua existência mais produtiva no invólucro da linguagem, da memória constituída por linguagem, da narrativa. De um eu que se desloca a um você sem deixar de ser $e u$, mas que, concomitantemente, transcende ao "documentismo" para consolidar uma relação que não se reduz a um "gélido" e "pálido" objeto de pesquisa como "ausência de presença", como "ausência de vitalidade". Quando a linguagem transcende e constitui a relação da Etno-história-oral, recria uma tropologia apropriada que significa as histórias de vida por meio da linguagem e do discurso emoldurado por uma narrativa; por suposto, a expressão " "trópico, de tropo, deriva de trópicos, tropos", que conota, para retóricos, gramáticos e teóricos da linguagem os “desvios do uso literal, convencional ou 'próprio' da linguagem, guinadas na locução que não são sancionadas pelo costume ou pela lógica”. Um tropo, não demarca apenas um “desvio de um sentido possível, próprio, mas também um desvio em direção a um outro sentido". Por isso, um tropo é sempre um deslocamento homólogo ao viés do discurso no qual, como gênero, predomina "o esforço para adquirir este direito de expressão, com crença total na probabilidade de que as coisas passam ser expressas de outro modo. E o emprego de tropos é, pois a alma do discurso, o mecanismo" por meio do qual o discurso efetiva o seu trabalho (WITHE, 1994, p. 14 - 15). Sem retroceder, em certo sentido, à noção da antropologia simbólica para a qual o mundo é texto e o discurso se manifesta no texto do mundo, a vida se torna discurso oralizado que pode ser ouvido, que pode ser visto como meio de apresentação à pesquisa científica descolada das grandes narrativas, das estruturas axiomáticas.

Por isso é que o corpo indígena fala e, no movimento de dizer, incorre em "discurrere" - expressão do latim que tende a encandecer "um movimento para a frente e para trás" ou um "deslocamento para cá e para lá” (WITHE, 1994, p. 16). Discurso é dança de narrativas. Decorre disso uma performance indígena, e negociada, da narradora em questão que, sem abdicar do sentido político, promove pelo menos três deslocamentos discursivos: (I) da estabilidade à instabilidade por meio de práticas

\footnotetext{
${ }^{6}$ Não se avoca Hayden Withe, neste artigo, para seguir os seus interessantes vieses epistemológicos e procedimentais, posto que tais investidas não se inscrevem em minhas preocupações deste ensejo. Apesar disso, considero que Withe define bem aquilo que, aqui, denomino de "tropologia".
}

Fronteiras: Revista de História | Dourados, MS | v. 19 | n. 34 | p. 280 - 301 | Jul. / Dez. 2017 
demonstradas pela repetição do arbítrio da ditadura militar refletido em dramas pessoais, familiares, (II) da desestabilidade à busca de ressignificação religiosa protestante por meio dos sentidos da conversão negociada com a religiosidade indígena, (III) da conversão à simbolização, à narração da memória machucada e ressentida que sustentou a inauguração dos artefatos narrativos da sobrevivência.

\section{ETNO-HISTÓRIA-ORAL DE QUEM? QUANDO? ONDE?}

Experiências da história oral brasileira e da história oral estrangeira têm demonstrado que, em alguns casos, em razão da multiplicidade das implicações éticas envolvidas em determinado projeto - em função do grande número de pessoas vivas ou de experiências dramáticas -, a(s) identidade(s) de quem narra pode(m) ser preservada(s). Quer seja por meio de pseudônimos como no caso da obra Augusto \& Lea: um caso de (des)amor em tempos modernos, escrita por Meihy (2006), ou, mais recentemente, de a Prostituição à brasileira: cinco histórias do mesmo autor (2015), trata-se de uma iniciativa de preservação. Sem demonstrar toda a identidade da narradora indígena que colaborou com a investida acadêmica ora procedida, apresento-a unicamente pelo nome com que é mesmo conhecida: Maria ${ }^{7}$. Natural das Terras Indígenas, TI, do norte do Paraná, na região de São Jerônimo da Serra, Maria nasceu em 1941 e tinha 23 anos à época do golpe civil-militar que instaurou a ditadura militar brasileira. Ao ser entrevistada no dia 14 de março de 2011, uma segunda-feira no início da tarde, Maria tinha $70 \operatorname{anos}^{8}$. Sempre residiu nas Terras Indígenas, TIs, entre São Jerônimo da Serra e Barão de Antonina - ambas no município de São Jerônimo da Serra, na bacia do rio Tibagi - conforme demonstrou Éder da Silva Novak em $A$ Povoação Indígena de São Jerônimo no Paraná $\left(1911\right.$ - 1922) ${ }^{9}$. Neste texto, Novak

\footnotetext{
${ }^{7}$ Nesse sentido, por ser Maria um nome comum, torná-la-ei “anonimada" por ocultar o seu sobrenome.

${ }^{8}$ A narradora faleceu no dia 13 de outubro de 2015.

${ }^{9}$ Formada no dia 30 de agosto de 1911, a Povoação Indígena de São Jerônimo se constituiu por meio do Decreto Federal $n^{\circ}$ 8.941. Mais tarde, a Lei do Estado do Paraná $n^{\circ} 2.113$, de 25 de março de 1922, almejou extinguir a Povoação Indígena referida e propôs a remoção dos indígenas da localidade. Para medir as consequências de todas as ações contrárias às populações indígenas de São Jerônimo, Novak analisou a legislação do período nas esferas federal e estadual, bem como o Serviço de Proteção aos Índios, SPI, e as obras pertinentes à questão apresentada (NOVAK, 2016). Ressalte-se que Novak abordou as problemáticas enfrentadas por indígenas no Paraná por meio de outros escritos igualmente pertinentes a começar de sua dissertação de mestrado: Tekohá e Emã: a luta das populações indígenas por seus territórios e a política indigenista no Paraná da Primeira República - 1889 e 1930 (2006); além de, entre outros textos: Desiguais e combinados: índios e brancos no vale do Rio Tibagi $-P R$ na primeira metade do século XX (2013).
}

Fronteiras: Revista de História | Dourados, MS | v. 19 | n. 34 | p. 280 - 301 | Jul. / Dez. 2017 
sinalizou que a etnia Kaingang "lideram com uma verdadeira Guerra de Conquista estipulada pela sociedade não indígena, que interessada nos recursos naturais, minerais e no aproveitamento mercantil das terras, promoveu um processo de expropriação" (NOVAK, 2016, p. 2) da terra em que estão os indígenas há mais de três mil anos (MOTA; NOELLI, 1999). Não suficientes as lutas pelas TIs, o relatório do GT sobre Graves Violações de Direitos Humanos no Campo ou contra os Indígenas, da CNV, abalizou os impactos dos períodos de arbítrio sobre as populações indígenas entre as quais a experiência de Maria se inscreve:

Como resultados dessas políticas de Estado, foi possível estimar ao menos 8.350 indígenas mortos no período de investigação da $\mathrm{CNV}$, em decorrência da ação direta de agentes governamentais ou da sua omissão. Essa cifra inclui apenas aqueles casos aqui estudados em relação aos quais foi possível desenhar uma estimativa. O número real de indígenas mortos no período deve ser exponencialmente maior, uma vez que apenas uma parcela muito restrita dos povos indígenas afetados foi analisada e que há casos em que a quantidade de mortos é alta o bastante para desencorajar estimativas (BRASIL - CNV, 2014, Vol. II, p. 199).

\section{MEMÓRIAS DE VIOLÊNCIA ENTRE EXPERIÊNCIAS FAMILIARES E POLÍTICO-RELIGIOSAS}

Ao ser recebido por Maria em sua residência feita de alvenaria, caracterizada pelo cuidado da arrumação de cada objeto no interior da casa, apercebi-me da carestia justificada de antemão - com certo acanhamento: "não repare..., pois é casa de gente pobre!". Caminhando no interior da casa como quem quer logo ouvir, deparei-me com o artesanato característico dos povos Kaingang não somente da região norte do Paraná: "se gostou, pode ir comprando...", disse-me Maria. Sentamo-nos na sala. Maria reclinou a fronte com leveza, e, na sequência, pôs as suas mãos - notadamente marcadas pelo trabalho - na região do queixo: "pode começar..." (Caderno de Campo, 2011, p. 12). Liguei, então, o gravador e, sem demonstrar pressa, anunciei o início da entrevista; mas, não fiz perguntas, interrupções bruscas ou direcionamentos decisivos à memória. Como costumeiramente, não me utilizei de "questionários" porque escolhi trabalhar com estímulos à performance criativa e no interregno da narração ${ }^{10}$.

${ }^{10} \mathrm{O}$ que proponho, amiúde, com fulcro na vivência do campo de pesquisa, é que a entrevista seja compreendida como uma espécie de trânsito no campo de sensibilidade e de objetividade sempre reelaborada, sempre rearranjada, do narrador. Escapo, portanto, nesta apresentação - diferentemente do que fiz anteriormente, das convencionais designações que perpassam a decomposição pretendida da

Fronteiras: Revista de História | Dourados, MS | v. 19 | n. 34 | p. 280 - 301 | Jul. / Dez. 2017 
Olhei para Maria e fiz um gesto positivo.

Ela iniciou, e, rompido o silêncio, transcorridos cerca de oito minutos de gravação, disse-me:

O nosso povo tem a tradição de servir na casa da noiva depois que casa. Não sei se você entende isso. Meu marido foi ajudar o meu pai, porque, além de tudo, sempre vivemos dificuldades [...] Meu pai ajudava numa plantação e meu marido também [...] Um dia a gente recebeu um homem viúvo em casa para trabalhar com a gente e ele começou a nos ensinar duas coisas: uma delas sobre Jesus, mas nada como na outra igreja de lá... Era um outro. Ensinou o evangelho cristão e a outra coisa é que Jesus gostava de gente pobre, de gente que não tinha nada e que ele era contra os homens do agronegócio que também queriam as nossas terras [...] Era um pastor batista que estava sem, como se diz? Sem igreja mesmo... porque também acreditava em uma vida social mais justa pra todos.

No fragmento apresentado, $a b$ initio, a narradora perfez por meio de sua história de vida uma tradição matrimonial conhecida de antropólogos como Juracilda Veiga, a qual apresentou em sua tese doutoral Cosmologia e Práticas Rituais Kaingang o cerimonial e a vida dos indígenas Kaingang em seu grupo doméstico: "Os Kaingang são uxorilocais como os demais Jê. A obrigação de servir ao sogro é mencionada em todas as áreas indígenas Kaingang por mim visitadas"; para Veiga, a obrigação de serviço ao sogro e de serviço da noiva "é uma obrigação moral e perene, pelo menos enquanto dure o casamento" (2000, p. 94). Apesar de o modus vivendi da uxorilocalidade não ser o mais apreciado contemporaneamente entre muitas famílias indígenas, os Kaingang se reportam a esse estilo específico de vida como alinhado às mais importantes tradições seladas entre um Kamé e um Kaĩru ${ }^{11}$. Ainda conforme

palavra "entrevista": "entre" e "vista", para denotar o campo de visibilidade ("entre vistas"), porque a fala, a narrativa, vai, por lógico, além do campo visual - embora os olhos também falem; instaura-se um momento de " $\pi$ oínбıৎ", "poiesis", em que a ressemantização, a ressignificação constante, ocorre durante todo o tempo em que o fluxo narrativo se impõe ao exercício da escuta. E o corpo do entrevistador não escuta apenas o que ouve, mas o que percebe, o que vivencia, o que lhe "toca" - donde, apresenta-se a intersubjetividade: quando um outro toca as paredes compartilhadas de sensibilidade. Entrevistar é transitar na medida em que se visita o outro e os seus avessos, nos versos, nos reversos e se escuta sobre a dor, o prazer, as frustrações, os êxitos cadenciados pela voz. É quando o entrevistador escuta com o corpo (In: SEAWRIGHT, 2017, p. 2015).

${ }^{11}$ No artigo Dinâmica social e familiar: uma descrição etnográfica de famílias de idosos Kaingang, consta que "etnografias realizadas com esta etnia destacam sua característica sociocosmológica de metades clânicas, denominadas de kamé e kairu. No mito de criação desta etnia estes seriam os nomes de dois irmãos gêmeos que surgiram da terra e originaram a sociedade Kaingang, cada um sendo o oposto do outro e estabelecendo com ele uma relação de complementaridade de características e forças. Assim sendo, tradicionalmente, na constituição familiar, é requerido que os casamentos ocorram entre indivíduos de metades opostas, ou seja, um indivíduo de metade kamé deve se casar com aquele cuja ascendência

Fronteiras: Revista de História | Dourados, MS | v. 19 | n. 34 | p. 280 - 301 | Jul. / Dez. 2017 
aduziu Veiga, se "um Kaĩru dá sua filha em casamento para o filho de um homem Kamé, este genro passará a residir na casa de seu sogro, onde gerará filhos para o seu clã, ou seja, para os Kamé. No entanto, estes filhos eram, portanto, criados com a família de sua esposa" - o que sinaliza para uma "troca de Kamé e Kaĩru” (2000, p. 94 95).

Receber, entrementes, um outro em casa não é uma prática incomum entre os Kaingang, sobretudo se se tratar de um viúvo ou de um solteiro que não tenha amparo familiar na aldeia. Notadamente, o homem recebido era um ministro protestante que apresentou-lhes alternativas nos prismas religioso e político ${ }^{12}$. Depreendo da narrativa segundo explicações posteriores da colaboradora - que o hóspede de Maria, de seu pai e do seu marido, estava desvinculado de uma igreja local em razão de ser politicamente alinhado à esquerda em uma denominação majoritariamente ortodoxa, anticomunista durante o período da Guerra Fria; Maria aclarou a questão quando contou que o ministro religioso ensinou-lhe certas noções, tais como: "alienação", "mais-valia". Em sua narrativa, a colaboradora avançou para informar que o pastor começou a fazer uma reunião na casa em que ela vivia com o marido e sua família; a reunião iniciava com orações típicas da piedade protestante, continuava com a leitura de um texto bíblico atinente às passagens com implicações sociais - segundo esclareceu -, e avançava para tratar da realidade do país, da região norte do Paraná ou, sobretudo, para a realidade dos povos indígenas no Brasil.

Inobstante, o ministro religioso demonstrou para o marido de Maria de qual maneira uma família poderia se tornar um "aparelho" para "resistir pela fé", segundo os termos da narradora, às ações do Estado. Ao contrário do que uma interpretação descuidada da teoria marxista poderia revelar por meio de frases reconhecidas e importantes, mas nem sempre tão bem interpretadas, como: "a religião é o ópio do povo", analisada inclusive por Michel Löwy em Marxismo e religião: ópio do povo? (2007, p. 298 - 315), diferentes grupos opositores da ditadura militar eram, ao mesmo tempo, marxistas e cristãos católicos ou protestantes conforme as variadas obras publicadas; entre estas obras, destaco a produção recente de Zózimo Trabuco (2016): À direita de Deus, à esquerda do povo: protestantismos, esquerdas e minorias (1974 -

seja kairu, identidade clânica que é herdada do pai, determinando a característica patrilinear desta etnia" (MOLITERNO; PADILHA; FAUSTINO; MOTA; CARREIRA, 2011, p. 839).

${ }^{12}$ Ledson Kurtz de Almeida demonstrou inclusive a presença de missões protestantes entre os Kaingang presentes no Estado do Paraná (In: TOMMASINO; MOTA; NOELLI, 2004, p. 285 - 315).

Fronteiras: Revista de História | Dourados, MS | v. 19 | n. 34 | p. 280 - 301 | Jul. / Dez. 2017 
1994). Para a temporalidade em análise circunscrita no presente artigo - descolada do período colonial brasileiro, abdica-se da expressão rígida de "cristianização" que denota um ou mais gestos verticais do agente dominante sobre corpos indígenas cristalizados e docilizados como "vítimas" da religião; abdica-se, pois, para assumir que um indígena pode ser protagonista em retomadas territoriais, em reinvindicações, em múltiplas negociações, mas, não menos importante, no ato de aderir às crenças distintas das originais pertencentes à cosmovisão de sua etnia. Por que não assumir que inclusive na conversão (conceito que não se pretende esmiuçar neste texto), pode acontecer o protagonismo indígena em teias complexas conforme apontou Pacheco de Oliveira (2016)? Em outros termos, a conversão - ou a adesão às diversas crenças - não apenas é uma possibilidade para quaisquer seres humanos conforme tem demonstrado a história e a sociologia da religião, mas se constitui como uma forma de se reinventar discursiva e narrativamente diante de novas realidades da mística em negociações constantes com as anteriores; com maior ou menor intensidade, com rupturas mais ou menos encandecidas, a conversão ou a "desconversão" denotam gestos que representam formas de incursões diferenciadas na memória coletiva além de serem, portanto, gestos possivelmente ligados às facetas do protagonismo indígena.

Superadas as fases iniciais da entrevista, notei que a colaboradora almejou mostrar peças de artesanato realizadas feitas à época da ditadura militar e, na sequência, algumas fotografias antigas; além de contar a história sobre como, por generosidade de uma amiga, foi possível ter uma fotografia mesmo vivendo em carestia e distante da ainda parca tecnologia no final da década de 1960, a narradora situou o tempo da convivência com o ministro religioso na casa de sua família: de 1967 a 1969. Revelouse, ao tempo da memória construída sobre o objeto biográfico, aquilo que disseram Juniele Rabêlo de Almeida, Maria Aparecida Blaz Vasques Amorim e Xênia de Castro Barbosa: "os objetos biográficos são construções do mundo material sobre as quais são projetadas experiências de vida do seu possuidor"; para as autoras mencionadas, os objetos biográficos se ancoram em "memórias e representações" (ALMEIDA; AMORIM; BARBOSA, 2007, p. 102). Sem conceder a fotografia - em torno da qual se desenvolveu o restante da entrevista -, para pesquisas futuras, e em razão de ainda nutrir medo das consequências de uma eventual publicação da imagem, Maria contou que funcionou em sua residência a partir de 1967 um grupo religioso que tinha feições políticas negociadas com os princípios de certa credulidade protestante: "a gente lia a 
Bíblia, a gente falava de justiça... da matança que os fazendeiros faziam nas Terras dos Índios... a gente falava, em segredo, sobre gente que sumia também. Que desaparecia e nunca mais voltava pra casa! E a gente alertava tudo de estranho". Temperada com os elementos de uma entrevista parcialmente realizada por meio do uso dos objetos biográficos associados aos estímulos à narração, a história de Maria ganhou retraços experienciais vívidos: "o narrador tira o que narra da própria experiência e a transforma em experiência dos que o escutam" - conforme Ecléa Bosi (1987, p. 43).

Enunciada, a experiência do tempo vívido e candente da memória se torna elemento discursivo para ressignificar tudo a partir até mesmo da dor, da alegria, do sofrimento ou da beleza. Neste caso, dor e sofrimento foram elementos presentes em uma estética narrativa do Sagrado que fez Maria se entregar ao sentimento religioso. Sobre a dor e o sofrimento, no relatório do GT sobre Graves Violações de Direitos Humanos no Campo ou contra os Indígenas, da CNV, considerou-se que: "com relação ao aprisionamento de índios, o Ato Institucional Número 5 (AI-5) foi um marco da oficialização desse sistema punitivo especial, integrando a repressão ao índio aos órgãos de controle exercidos por parte do Estado brasileiro, como SNI" e seus afluentes. Nesse direcionamento, a repressão se estendeu de maneira "coordenada contra indígenas de várias regiões do país, atingindo também funcionários da Funai, antropólogos, indigenistas, religiosos e suas entidades" (BRASIL - CNV, 2014, Vol. II, p. 199) ${ }^{13}$.

Depois do AI-5, já no ano de 1969, os generais do Exército Brasileiro Costa Cavalcanti, como ministro do Interior, e Bandeira de Melo, como presidente da FUNAI, foram responsabilizados pelos governistas para tratarem da "política indigenista" da República de exceção. A partir da década de 1970, o governo brasileiro tomou, pois, medidas no afã de continuar aprimorando os preceitos repressivos como sequência do efeitos do AI-5 sobre a população indígena, e, por conseguinte, para adensar a política de repressão aos indígenas no país: “a partir de 1970, com a edição do Decreto no 66.882, a Funai incorpora formalmente atividades de assessoramento de segurança e informações à sua estrutura organizacional, por meio de uma Seção de Segurança e Informações", vinculada à

Divisão de Segurança e Informações (DSI) do Ministério do Interior. Em 1975, é publicado, através da portaria no 239, o regimento interno

\footnotetext{
13 Nesse sentido, o relatório elucidou os papeis punitivos, não obstante, no âmbito da SPI e, como constante nesta mesma citação, no interior da FUNAI (BRASIL - CNV, 2014, Vo. II, p. 234 - 239).
}

Fronteiras: Revista de História | Dourados, MS | v. 19 | n. 34 | p. 280 - 301 | Jul. / Dez. 2017 
da Assessoria de Segurança e Informações (ASI-Funai), tal como passa a ser chamada, que regulamenta suas finalidades, intrinsecamente ligadas à adequação da Fundação à Doutrina da Segurança Nacional. Através da portaria, todas as unidades descentralizadas da Funai passam a compor a "comunidade de informações" da ASI, o que se reverte na instauração de um clima constante de perseguição dentro do órgão (BRASIL - CNV, 2014, Vol. II, p. 241) ${ }^{14}$.

Não somente as TIs estavam permanentemente em risco por conflitos apontados pela historiografia, porém, a partir do adensamento da repressão aos indígenas, criou-se um aparato informativo e que agiu de forma recrudescida contra os direitos humanos das diferentes etnias nas mais variadas partes do Brasil. Tinha-se, agora, contra a Segurança Nacional e contra o Estado brasileiro - como "inimigo interno" - a categoria do "índio comunista": mais nocivo do que um "silvícola" comum. A história dramática de Maria entrelaçada à de sua família se desenvolveu antes mesmo da organização das Assembleias de Chefes Indígenas corriqueiramente propostas pelo Conselho Indígena Missionário, CIMI, na década de 1970. O ambiente de repressão que atingiu Maria e sua família era nacional e demarcou uma política de Estado:

Um exemplo desse ambiente de repressão pode ser visto na área de atuação da $4^{a}$ Delegacia Regional da Funai, sediada em Curitiba, e que atendia os indígenas dos três estados da região Sul. Diversas lideranças indígenas Kaingang e Guarani de Santa Catarina, do Paraná e do Rio Grande do Sul participavam das chamadas "Assembleias de Chefes Indígenas", organizadas com o apoio do CIMI desde 1974 (BRASIL - CNV, 2014, Vol. II, p. 242).

Acerca do processo de urdidura do ambiente hostil aos indígenas - para além da estrutura mesma aparato de repressão, Maria retraçou a narrativa de sua dor iniciada no ano de 1969 - contexto imediato das ações apresentadas acima com o aporte documental da CNV:

\footnotetext{
${ }^{14}$ Chamaram a atenção dos redatores do mencionado GT da CNV dois artigos do regimento:

Art. 19 - A Assessoria de Segurança e Informações (ASI) da Fundação Nacional do Índio é órgão subordinado diretamente ao Presidente da FUNAI e encarregado de assessorá-lo em todos os assuntos pertinentes à Segurança Nacional e às Informações Setoriais da sua área de atuação, sem prejuízo da condição de órgão sob a supervisão e coordenação da Divisão de Segurança e Informações do Ministério do Interior (DSI/Minter).

Parágrafo único: O ASI é o elemento através do qual a Funai integra a comunidade setorial de informações do Ministério do Interior (CSI-MINTER).

(...)Art. 89 - Ao Setor de Segurança compete:

(...)IV - propor as medidas de Contra-informação e de Segurança Orgânica
}

Fronteiras: Revista de História | Dourados, MS | v. 19 | n. 34 | p. 280 - 301 | Jul. / Dez. 2017 
Até que prenderam o pastor. Ficamos sozinhos e continuamos o trabalho. Esse homem..., ele era de um grupo, acho, de guerrilheiros e era de São Paulo [...] era guerrilheiro como somos guerreiros, nossa gente [...] Não temos problemas com a guerra [...] Era trabalhador! Ajudava em nossa casa. Depois, voltaram no início de 1969; levaram o meu marido, mas veja: a gente não só se reunia na nossa antiga casa... a gente alimentava as pessoas, conseguia informações e guardava uns documentos que nos pediam. E a gente protestava também! Quando levaram o meu marido a gente já era da igreja que funcionava na nossa casa: orei a Deus, mas nunca deixei tudo da sabedoria de nós, índios, até porque Deus está em tudo [...] A religião me ajudou a sobreviver [...] Bateram muito no meu marido, sabe? Até choques... até penduraram ele em um pau nos punhos, tudo... ele sofreu muito e se agarrou em Deus. Fiquei sozinha... a gente tinha um filho, já, acredita? Eles choraram muito.

Segundo a colaboradora, seu marido foi sequestrado pelos agentes da repressão por duas vezes consecutivas no ano de 1969. A última vez que Maria o viu foi na segunda prisão, quando foi amarrado e "jogado", como disse a narradora, em uma viatura do Exército Brasileiro que atuava juntamente com policiais civis na região. A interlocutora disse, em situação de entrevista, que: "existem rumores de que aqueles homens experimentaram a tortura com o meu marido, para treinar mesmo", isto é, de que aquele indígena foi tomado para, entre outras coisas, além de sofrer por razões comuns ao arbítrio perpetrado pela ditadura, servir de cobaia à repressão. Donde, justificam-se as investidas do relatório da CNV em demonstrar a prática dos repressores em tomar pessoas para servirem como "cobaias" (BRASIL - CNV, 2014, Vol. III, p. $325,351,366,425)$.

A partir do último sequestro por agentes do Estado, entrementes, Maria e o seu filho tiveram de continuar a trajetória de vida com o apoio do seu pai e dos seus irmãos. O desaparecimento forçado do esposo de Maria impulsionou uma nova fase de reelaboração da luta da narradora e de criação do espaço de luto. Sendo a mãe de Maria falecida ao tempo dos episódios narrados, a colaboradora descreveu o seu luto da viuvez presumida sempre tratado na perspectiva da mensagem cristã da consolação e do conforto espiritual, porém com ressentimento assumido que atendeu uma política de memória individual e coletiva mais ou menos alinhada às formulações genealógicas propugnadas por Pierre Ansart em sua História e Memória dos Ressentimentos (In: BRESCIANI; NAXARA, 2004, p. 30 - 34).

Embora o pavor da tortura contado por seu marido a assolasse - por ocasião da sua primeira prisão -, a narradora decidiu continuar os trabalhos de "pregação do 
evangelho", como gosta de dizer, e, ao mesmo tempo, de resistência política ou da mobilização de algumas famílias indígenas espalhadas nas TIs do norte paranaense. Por essa razão, Maria, outrossim, foi presa, torturada, sofreu com os atos variados e repetidos de violência sexual dos agentes do Estado brasileiro:

Achei que iria morrer [...] Foi um terror [...] Estavam me destruindo por dentro [...] Eu já estava destruída. Era viúva! Eles eram os responsáveis por isso [...] Ai... como é difícil narrar, agora [...] Parece que era uma criminosa, mas alimentava as crianças da aldeia [...] $\mathrm{O}$ que tem de mais a gente ser bom com os outros? Claro que a gente estava organizando um grupo pra levantar contra eles, mas não tinha outro jeito [...] O pastor que foi preso e sumiu ensinou pra gente que tinha que fazer alguma coisa [...] Não poderia alienar mais [...] Que o Reino de Deus, que eu não excluo a sabedoria espiritual do meu povo, não iria vir sem luta [...] Apanhei muito que nem lembro de tudo [...] Daí eles me, me... estupraram. Um, dois, três, quatro homens. Que vergonha, mas o tempo todo eu estava sofrendo pela nossa gente. Não pelo país só, mas pelo povo indígena [...] Não consigo falar tudo.

Evidentemente, Maria não conseguiu narrar tudo, como disse, em razão do aspecto traumático e da dificuldade em perlaborar esse mesmo trauma. Convém dizer que para autores como Dominick LaCapra o luto é um aspecto importante da teoria psicanalítica quando em seu cruzamento com a escrita histórica para além da individualidade de quem o sofre, pois os aspectos sociais de luto: "podem ser o único modo efetivo de superar parcialmente a melancolia e a depressão ou, pelo menos, de preveni-las de se tornarem desgastantes e incapacitadoras" (LACAPRA, 1998, p. 184) $)^{15}$. Mas, aquilo que se inscreveu no âmbito do dizível - verificável na narrativa abordada -, trilhou o ressentimento por três importantes sentidos nas análises percorridas por David Konstan em seu texto Ressentimento - História de uma Emoção: o (1) sentido psicológico de ressentimento caracterizado por meio de "algo como a raiva ou a irritação perante uma desfeita" em larga escala que alimenta "um sentimento duradouro, não fugaz: o ressentimento é cultivado e acalentado"; o (2) sentido social de ressentimento que diz respeito questões de pertencimento à grupos cujas trajetórias perpassarem vieses de injustiças ou parcialidades; finalmente, o (3) sentido existencial do ressentimento tratado por Konstan por meio das chaves teóricas de Dostoievski,

\footnotetext{
${ }^{15}$ Para uma reflexão sobre aspectos psicanalíticos entrecruzados com a história, verificar a tese defendida por Johnny Roberto Rosa: À perlaboração de um passado traumático: do reconhecimento das vítimas e atrocidades do passado à superação dos legados das experiências de violência da ditadura civil-militar no Brasil (2017).
}

Fronteiras: Revista de História | Dourados, MS | v. 19 | n. 34 | p. 280 - 301 | Jul. / Dez. 2017 
Nietzsche, Max Scheler, Heidegger - entre outros (In BRESCIANI; NAXARA, 2004, p. 61 -62). Scheler, citado por Konstan, constatou que "[Ressentimento é] uma atitude mental duradoura, causada pela repressão sistemática de certas emoções e afetos que são componentes normais da natureza humana", porque "a repressão dessas emoções leva a uma tendência constante de se permitir atribuir valores incorretos e juízos de valor correspondentes" (SCHELER, 1998, p. 29). Apesar da consideração ao aparato teórico sobre ressentimento e as suas molduras mais cientificamente aceitas, a história oral etnográfica, atravessada por discursos, garantiu o registro da posição de Maria para além de aportes europeus e formais: “[...] já fui muito criticada por outros indígenas por falar nisso [...] nessa ideia de perdão, porque dizem que é algo dos colonizados pelos cristãos [...] só que eu consegui caminhar o caminho do perdão individual: não social, porque o Estado não puniu ninguém".

Maria sofreu com o modus operandi da ditadura militar contra si mesma como indígena, como alguém cujo discurso político foi reprimido e como mulher; também contra a sua própria família e contra a estabilidade emocional experimentada não obstante ter sido, conforme relatou, estuprada e ter sofrido com a violência em uma unidade de repressão que não soube dizer onde se localizava ${ }^{16}$. No decurso da narrativa, Maria descreveu a tristeza com que se abateu por ter sido vigiada, presa, torturada, e, antes, por ter sofrido com o sequestro do marido, bem como por ter a vida familiar desorganizada, agredida, desfeita.

\section{ENTRE RITOS E RESISTÊNCIAS: A SOBREVIVÊNCIA}

Todavia, a história de Maria atravessou o tempo da agressão por meio do fortalecimento de suas convicções político-religiosas, discursivas, como instrumentos de superação dos episódios dramáticos experimentados a partir dos eventos contados: "o meu ciclo de dores não terminou com a ditadura porque ninguém foi punido, mas depois

\footnotetext{
${ }^{16}$ Na parte do relatório da CNV dedicada à Violência Sexual, Violência de Gênero e Violência contra crianças e adolescentes, consta o seguinte sobre tais ações vilipendiadoras: "A violência sexual, exercida ou permitida por agentes de Estado, constitui tortura. Por transgredir preceitos inerentes à condição humana, ao afrontar a noção de que todas as pessoas nascem livres e iguais em dignidade e direitos, a normativa e a jurisprudência internacionais consideram que a violência sexual representa grave violação de direitos humanos e integra a categoria de "crimes contra a humanidade".1 No cumprimento de seu mandato, ao buscar promover o esclarecimento circunstanciado de casos de tortura ocorridos durante a ditadura militar, a Comissão Nacional da Verdade (CNV) pôde constatar que a violência sexual constituiu prática disseminada do período, com registros que coincidem com as primeiras prisões, logo após o golpe de Estado" (BRASIL - CNV, 2014, Vol. I, p. 400).
}

Fronteiras: Revista de História | Dourados, MS | v. 19 | n. 34 | p. 280 - 301 | Jul. / Dez. 2017 
de tudo o que passei... fortaleci por dentro as minhas convicções todas [...] meu povo me ajudou", explicou. Os Kaingang têm, segundo Veiga, três importantes rituais que constituem a sua cosmologia: a festa do Kuiâ (xamã) ${ }^{17}$, a festa do Kikikoi $^{18}$ e o ritual de purificação da viúva. A autora disse que tais rituais preenchem o significado do que nominou "os três tempos do mundo" nos ciclos aclarados de conflagração e regeneração da terra. Nesse sentido, os rituais dos Kaingang elencados por Veiga se referem à agricultura, à volta dos mortos em festa de confraternização entre os vivos e os mortos, assim como na separação desses espaços de existência entre os vivos e os mortos. Para os Kaingang, a vida terral toma contornos de significação dados por ancestrais mortos ou por pessoas mortas que tinham grande significado à vida cotidiana, à cosmologia. Segundo Veiga, portanto, os três tempos do mundo são um artifício narrativo para explicar a cosmologia Kaingang.

$\mathrm{Na}$ urdidura da cosmologia Kaingang, um dos rituais persistentes - mas realizado com muito mais vivacidade nas décadas de 1960 e de 1970 é o de purificação da(o) viúva(o) -, que ainda consiste, tradicional e tenazmente, em "separar, do morto recente, os vivos do grupo doméstico. Restituindo ao vivo - no caso, a(o) viúva(o) - as substâncias próprias que eram partilhadas com aquele que morreu" (VEIGA, 2000, p. 278).

Por conseguinte, faz-se:

Um duplo movimento: o primeiro, restituindo ao cônjuge vivo sua energia vital desestruturada pela súbita ruptura dessa mesma energia que era, antes, partilhada com o cônjuge que morreu; num segundo movimento, liberando o morto das amarras que o mantinham preso ao mundo dos vivos. Esse morto, agora livre dos sentimentos que ainda prendiam aos vivos, segue para o mundo dos mortos. No entanto, como morto recente há sempre o risco de que ele venha a perambular pelo espaço dos vivos. O Ritual do Kiki é necessário para lhe dar o

\footnotetext{
${ }^{17}$ Para Veiga, "a Festa do Mastro - ou, Festa do Kuiâ - refere-se a um primeiro tempo do mundo, quando a terra foi criada como espaço habitável pelos humanos e outros seres, e tem na pessoa do Kuiâ, o xamã Kaingang, a figura central, o mediador, que realiza a ligação dos humanos com seres do tempo primordial, obtendo os seus favores representados pela fertilidade do solo, das mulheres e pela estabilidade da terra. Em troca, é homenageado em um ritual anual onde a comunidade reconhece os benefícios recebidos e agradece a proteção do Kuiâ/iangrõ através de uma festa de comensalidade e do rito de levantamento do mastro" (2000, p. 277).

${ }^{18}$ Ainda segundo Veiga, "a Festa do Kikikoi marca o segundo tempo do mundo, onde surge efetivamente a sociedade Kaingang, depois da catástrofe primordial do dilúvio que destruiu a primeira humanidade. Portanto realiza o retorno a uma sociedade exemplar, tal qual foi criada no princípio. Esse ritual é dependente dos rezadores, que são os donos dos cantos poderosos que abrem e fecham caminhos. Sem o número suficiente de rezadores, não é mais possível a todas as áreas indígenas realizar esse ritual que permite o intercâmbio entre vivos e mortos" (2000, p. 277).
}

Fronteiras: Revista de História | Dourados, MS | v. 19 | n. 34 | p. 280 - 301 | Jul. / Dez. 2017 
entendimento e permitir que, sendo integrado à comunidade dos mortos passa voltar a nascer novamente (VEIGA, 2000, p. 278).

Como parte do universo Kaingang, Maria se questionou - depois do desaparecimento forçado de seu esposo e intenso sentimento de perda -, se deveria, tendo-se convertido ao protestantismo, ainda assim, participar do ritual de purificação em razão de sua viuvez. Em seu estudo, Veiga constatou haver resistência ou, como abalizou, "desestruturação das práticas rituais tradicionais dos Kaingang” entre os indígenas que são cristãos católicos e protestantes. Para Veiga, "católicos e crentes jogam com a mesma ficha"; os "crentes afirmam que só eles serão salvos porque 'se entregam a Jesus', abandonando seus rituais antigos" e, por seu turno, "os católicos, que são praticantes dos antigos ritos Kaingang, contestam com a certeza de que aqueles que se negam a 'receber a reza' tornam sua morte definitiva" (VEIGA, 2000, p. 279). A narrativa de Maria, sobre a dor de sua perda, decorrente de graves violações do Estado brasileiro, e perpetradas por agentes da repressão, demonstrou um processo de negociação cultural para além da questionada noção de sincretismo religioso. Porque sendo protestante, mesmo inscrita no universo descrito por Veiga, Maria não recusou participar do ritual de purificação para, como aduziu, "liberar o esposo para o seu destino...". Se a narrativa de Maria contribuiu para evitar descrições etnográficas generalizantes e inespecíficas - não sendo este o caso do importante estudo de campo feito por Veiga, ao mesmo tempo corroborou com o processo de individuação da interlocutora no ato narrativo como elo entre as memórias individual e coletiva:

Não sei dos outros indígenas [...] O Estado, como diz, né?.. Ele tirou minha família. Meu pai era idoso e veio a falecer triste numa cama, nervoso e em razão do que houve comigo [...] Eu sofri todo tipo de agressão também: tenho vergonha de falar [...] Mesmo sendo protestante, como eu digo, não fui na 'onda' dos outros parentes que não quiseram mais os rituais [...] Acho que Jesus gosta das tradições indígenas, dos saberes [...] E foi aí que pensei: preciso tratar minha dor e nada melhor do que as tradições dos nossos antepassados para isso [...] meu marido morreu e ficaria de alguma forma perturbado, não foi qualquer morte, e eu fiz, sim, o ritual da purificação da viúva porque precisava superar aquela fase [...] como se diz: deixar fazer a passagem e fazer a passagem para outra fase. Mas eu creio que Topẽ enviou seu único filho.

Ao fitar a sua sobrevivência inclusive emocional, para além das agressões físicas, mas, provavelmente, em decorrência dos dramas sofridos em uma unidade de 
repressão ditatorial, Maria se permitiu negociar entre mitologias e rituais como formas de continuar a vida, de sobreviver. De forma axial, Maria sustentou a crença em Topẽ e disse, entretanto, que ele enviou o seu único filho em uma clara intersecção - em evidente negociação - com o dogma cristão retraçado. No entanto, o caminho de tratamento de sua sobrevivência encontrou frinchas de explicações, de subjetividades discursivas e de apaziguamentos da dor por meio dos significados místicos, religiosos. Como apontou Pierre Sanchis em As tramas sincréticas da história: sincretismo e modernidades no espaço luso-brasileiro, entre outros textos, o "tema do sincretismo no Brasil" sofreu, "nos últimos vinte anos, uma série de objeções" (1995); tais objeções não se restringem às hierarquizações de crenças ou de saberes, das culturas e ao efeito de juízo realizado por teólogos ou líderes cristãos sobre lideranças de outras expressões religiosas ou de religiosidades variadas. Não se trata de simples mistura ou de uma suposta dialética de saberes; tampouco de mistura fortuita e irracional, mas de uma racionalidade compósita, sagaz, que é capaz de ligar, fio a fio, vis-à-vis, nos tecidos culturais, nos tecidos dos saberes em prol de sobrevivências. Nem sempre é assim, pois o rezador Kaingang Irinei Xorimbâg Pinheiro, rezador dos Kamé-Wonhétky, disse para Veiga que são necessários os rituais kiki para promover a passagem dos mortos para a aldeia dos mortos, mas que igualmente nos velórios havia rezas que cumpriam as mesmas funções; entrementes, disse Irinei Xorgimbâg Pinheiro que "os crentes" não "recebem a reza", pois não estão abertos ao entendimento sobre a boa condução dos espíritos após a morte (VEIGA, 2000, p. 278).

Da entrevista com Maria, porém, depreende-se de que existe uma preocupação da narradora com o caminho do espírito do marido, sim, mas que, ao mesmo tempo, ela não abdica da religiosidade política entalhada por sua história de vida e por sua narrativa de sobrevivência que lhe deu condições de superar os dramas mencionados; tais superações ocorreram, nas categorias de Homi K. Bhabha, entre-lugares, entre-tempos e com base em hibridismos: na medida em que a identidade foi negociada sem se perder, também a memória se abriu à negociação da dor e promoveu discursos sobreviventes sem esquecimentos passivos ou relapsos. Em Bhabha, do ponto de vista teórico, tanto quanto na narrativa de Maria, do ponto de vista experiencial, a sobrevivência se estabelece nos espaços assimétricos onde as identidades se tornam discursos e são resistentemente pluralizadas (1998, p. 26). Nesse sentido, as negociações com/de identidades religiosas partícipes de culturas intrincadas são estratégias que induzem a superação de visões 
monolíticas sobre os cristianismos, as políticas, as ideologias e as suas (in)capacidades coloniais. Ao fim e ao cabo, Maria foi uma protagonista político-religiosa diante de mais um momento de "exceção como regra" da história política brasileira que outra vez categorizou com rigidez o índio, colocando-o como "inimigo do Estado" e como "ameaça" para a segurança nacional.

\section{REFERÊNCIAS BIBLIOGRÁFICAS}

ALMEIDA, Juniele Rabêlo; AMORIM, Maria Aparecida Blaz Vasques; BARBOSA, Xênia de Castro. Performance e Objeto Biográfico: questões para a história oral de vida. Revista Oralidades (USP), v. 2, p. 101 - 109, 2007.

ANSART, Pierre. História e Memória dos Ressentimentos. In: BRESCIANI, Stella; NAXARA, Márcia (Orgs.). Memória e (res)sentimento: indagações sobre uma questão sensivel. Campinas: Editora da Unicamp, 2004.

BAUER, Caroline Silveira. Como será o passado?: História, historiadores e a Comissão Nacional da Verdade. São Paulo: Paco Editorial, 2017.

BHABHA, Homi. K. O local da cultura. Belo Horizonte: Editora UFMG, 1998.

BOSI, Ecléa. Memória e Sociedade. Lembranças de velhos. São Paulo, EDUSP, 1987.

Brasil. Comissão Nacional da Verdade. Relatório/Comissão Nacional da Verdade. Brasília: CNV, 2014. 976 p. - (Relatório da Comissão Nacional da Verdade; v. 1).

Brasil. Comissão Nacional da Verdade. Relatório/Comissão Nacional da Verdade. Brasília: CNV, 2014. 416 p. - (Relatório da Comissão Nacional da Verdade; v. 2). Brasil. Comissão Nacional da Verdade. Relatório/Comissão Nacional da Verdade. Brasília: CNV, 2014. 1996 p. - (Relatório da Comissão Nacional da Verdade; v. 3).

CAVALCANTE, Thiago Leandro Vieira. Colonialismo, Território e Territorialidade: a luta pela Terra dos Guarani e Kaiowa em Mato Grosso do Sul. Jundiaí: Paco Editorial, 2016.

Etno-história e história indígena: questões sobre conceitos, métodos e relevância da pesquisa. Rev. História/Franca, v. 30, n. 1, p. 349-371, Jun., 2011.

CLIFFORD, James. A experiência etnográfica: antropologia e literatura no século XX. Rio de Janeiro: Editora UFRJ, 2002.

GONÇALVES, Carlos Barros. Até os confins da terra: o movimento ecumênico protestante no Brasil e a evangelização dos povos indígenas. Dourados: Ed. UFGD, 2011.

HALBWACHS, Maurice. Les cadres sociaux de la mémoire. Paris: Librairie Félix Alcan,

1925. A memória coletiva. São Paulo: Vértice, 1994.

\& Cultura. Rio de Janeiro/UFRJ, Vol. 4, nº 7, jan-jun./2017.

LACAPRA, Dominick. History and memory after Auschwitz. U.S.A.: Cornell University Press, 1998. 
LÖWY, Michel. Marxismo e religião: ópio do povo? CLACSO. Buenos Aires: Consejo Latinoamericano de Ciencias Sociales, 2007.

MEIHY, José Carlos Sebe Bom. Manual de História Oral. 5a ed. São Paulo: Edições Loyola, 2005.

; HOLANDA, Fabíola. História Oral, como fazer, como pensar. São Paulo: Editora Contexto, 2013.

MOLITERNO, Aline Cardoso Machado; PADILHA, Amanda Marques; FAUSTINO, Lúcio Tadeu Mota; CARREIRA, Lígia. Dinâmica social e familiar: uma descrição etnográfica de famílias de idosos Kaingang. Ciência, Cuidado e Saúde, v. 10, p. 836 844, 2011.

MONTEIRO, John Manuel. Negros da Terra - índios e bandeirantes nas origens de São Paulo. São Paulo: Cia. das Letras, 1994.

MOTA, Lúcio Tadeu. A Guerra de Conquista nos Territórios dos Índios Kaingang do Tibagi. Revista de História Regional 2, Ponta Grossa, v.1, p. 187-207, 1997.

A presença indígena no vale do Rio Tibagi/PR no início do século XX. Revista Antítese, v. 7, n. 13, p. 358-391, jan./jun. 2014.

. As colônias indígenas no Paraná provincial. Curitiba: Aos Quatro Ventos, 2000.

NOELLI, Francisco Silva. A pré-história da região onde se encontra Maringá, Paraná. In: DIAS, Reginaldo Benedito; GONÇALVES, José Henrique Rollo. (Org.) Maringá e o Norte do Paraná. Maringá: EDUEM, 1999.

NAPOLITANO, Marcos. 1964: História do Regime Militar Brasileiro. São Paulo: Editora Contexto, 2014.

NOVAK, Éder da Silva. A Povoação Indígena de São Jerônimo no Paraná (1911 1922). In: XV Encontro Regional de História (100 anos da guerra do Contestado: historiografia, acervo e fontes), 2016, Curitiba, PR. Anais (on-line). Disponível em: http://www.encontro2016.pr.anpuh.org/resources/anais/45/1468841866_ARQUIVO_A PovoacaoIndigenadeSaoJeronimonoParana(1911-1922).pdf Acesso em 16 de dezembro de 2017.

OLIVEIRA, João Pacheco de. O nascimento do Brasil e outros ensaios: "pacificação", regime tutelar e formação de alteridades. Rio de Janeiro: Contra Capa, 2016.

SANCHIS, Pierre. As tramas sincréticas da história. Revista Brasileira de Ciências Sociais, São Paulo, v. 28, p. 123-138, 1995.

SCHELER, Max. Ressentiment. Milwaukee: Marquette University Press, 1998.

SEAWRIGHT, Leandro A. Entrevistar é transitar: uma passagem por histórias de vida, de religiosos, de resistentes e de apoiadores da ditadura militar brasileira - seis entrevistas. Revista Poder \& Cultural, Rio de Janeiro, Vol. 4, Nº 7, pp. 214 - 219, 2017.

; ROVAI, Marta (Org.). Memórias do Regime Militar no Brasil e uma Justiça de Transição Inacabada: vozes, propostas, estudos. Revista Poder \& Cultural, Rio de Janeiro, Vol. 4, No 7, pp. $214-219,2017$.

TRABUCO, Zózimo. À direita de Deus, à esquerda do povo: Protestantismos, esquerdas e minorias (1974 - 1994). Salvador: Sagga, 2016. 
TOMMASINO, Kimiye; MOTA, Lúcio Tadeu; NOELLI, Francisco Silva (Orgs.). Novas contribuições aos estudos interdisciplinares dos Kaingang. Londrina: Eduel, 2004.

WITHE, Hayden. Trópicos do discurso: Ensaios sobre a Crítica da Cultura. São Paulo: Editora da Universidade de São Paulo, 1994.

Recebido em: 02/08/2017

Aprovado em: 06/12/2017 